\title{
Avaliação quantitativa do conforto térmico de uma cidade em área de transição climática: Feira de Santana-Bahia, Brasil ${ }^{1}$
}

\author{
Rosângela Leal Santos², Henrique Oliveira de Andrade ${ }^{3}$
}

\begin{abstract}
RESUMO
Este artigo apresenta-se como uma tentativa de quantificar o conforto térmico da cidade de Feira de Santana, localizada em área de transição entre o clima úmido do litoral e a região semi-árida do Nordeste brasileiro. Para isso utilizouse o Índice de Temperatura Efetiva (TE) proposto por Thom \& Bosen (1959). A metodologia baseia-se numa discussão, seguida de uma análise das teorias de conforto térmico mais importantes numa perspectiva da climatologia geográfica e, em seguida, é realizada a aplicação dos dados climáticos de Bulbo Seco e Úmido para a elaboração do índice. Assim, foram utilizados os dados climatológicos entre os anos de 1998 a 2006. Dentre as teorias supra citadas, destacam-se a de Monteiro (1976), a de Thom \& Bosen (1959), e o Índice de Windchill (TW). Quanto aos resultados, constataram-se períodos com um grande índice de TE, isto é, altas taxas de conforto térmico e períodos com mais baixos valores, ocorrem na mesma época do ano, nos meses de primavera.
\end{abstract}

Palavras-chave: Clima urbano, conforto térmico, Índice de Thom (1959).

\begin{abstract}
This article is an attempt to quantifying the thermal comfort of a city located in a transition area between the coastal humid climate and the semi-arid region of the northeastern Brazil. For this the Temperature Effective Index (TE) by Thom (1959) was used. The methodology is based on a discussion, followed by an analysis of the more important theories about thermal comfort in a geographic climatologic perspective and the Dry and Humid Bulb climatic data application for the index elaboration. Amongst the theories used it was distinguished the Monteiro (1976), Thom (1959), and the Windchill Index (TW). In the results, periods of higher (TE) index, that is higher thermal comfort taxes, and the periods of lower index that is lower thermal comfort taxes occur in the same year period, in the spring months.
\end{abstract}

Key words: Urban climate, thermal comfort, Index of Thom (1959).

1 Resultados finais do Projeto de Iniciação científica financiado pela Fundação de Amparo a Pesquisa do Estado da Bahia (FAPESB), intitulado "A urbanização e seus impactos nas características climáticas na cidade de Feira de Santana-BA" no período de julho de 2006 a julho de 2007. Artículo recibido el 3 de agosto de 2007 y aceptado el 19 de junio de 2008.

2 Professora Dra. em Engenharia dos Transportes da Universidades do São Paulo (USP) - Professora
Assistente da Universidade Estadual de Feira de Santana (UEFS) - Departamento de Tecnologia / Coordenadora da Estação Climatológica Feira de Santana - Bahia (Brasil). E-mail: rosaleal@uefs.br

3 Graduando do Curso de Licenciatura e Bacharelado em Geografia pela Universidade Estadual de Feira de Santana - Bahia (Brasil). E-mail: henriqueuefs@ig.com.br 
Quando se pretende discutir o conforto térmico urbano, estamos nos referindo ao clima urbano que, segundo Lombardo (1985: 22), se define como "um sistema que abrange o clima de um dado espaço terrestre e sua urbanização. É um mesoclima que está incluído no macroclima e que sofre, na proximidade do solo, influências microclimáticas derivadas dos espaços urbanos".

Segundo Fanger (1970), o conforto térmico é uma condição da mente que expressa a satisfação do indivíduo com o ambiente térmico. Nesse sentido, o conforto térmico pode ser analisado como sendo as trocas térmicas que dependem de vários fatores, sejam eles ambientais e/ou pessoais, comandados por processos físicos.

A justificativa deste artigo está na compreensão do comportamento dos elementos climáticos na escala de microclima da cidade de Feira de SantanaBA, caracterizada de porte médio, com o intuito entender e diagnosticar a variabilidade do conforto térmico e posteriormente intervir em um futuro planejamento urbano-climático para a mesma utilizando as características térmicas da superfície como parâmetro de análise.
Este artigo apresenta primeiramente uma introdução com os aspectos gerais acerca da temática em estudo, seguido de uma caracterização geoambiental enfocando o clima Semi-Árido, uma discussão metodológica sobre as diversas formas de qualificar e quantificar o conforto térmico pra, em seguida, promover uma estimativa do conforto térmico para a cidade de Feira de Santana-BA (Figura № 1).

\section{Caracterização geoambiental da área de estudo}

O município de Feira de Santana-BA destaca-se pelo seu poder sócio-espacial caracterizada por ser o maior entroncamento rodoviário do Norte-Nordeste do Brasil, com uma população em torno de $500 \mathrm{mil}$ habitantes. O município possui uma extensão aproximada de $1.350 \mathrm{~km}^{2}$. Quanto à cidade, destaca-se pelo seu potencial de comércio e indústria. No seu processo de urbanização, o Centro Industrial do Subaé (CIS) caracterizouse como um grande agente atrativo de imigrantes. Atualmente, evidencia-se o processo de verticalização da cidade com um aumento significativo no quantitativo de prédios de grande e médio porte no centro e nos bairros adjacentes (Figura $\mathrm{N}^{\circ} 3 \mathrm{~b}$ ).

Figura $\mathrm{N}^{0} 1$

LOCALIZAÇÃO DO MUNICÍPIO DE FEIRA DE SANTANA

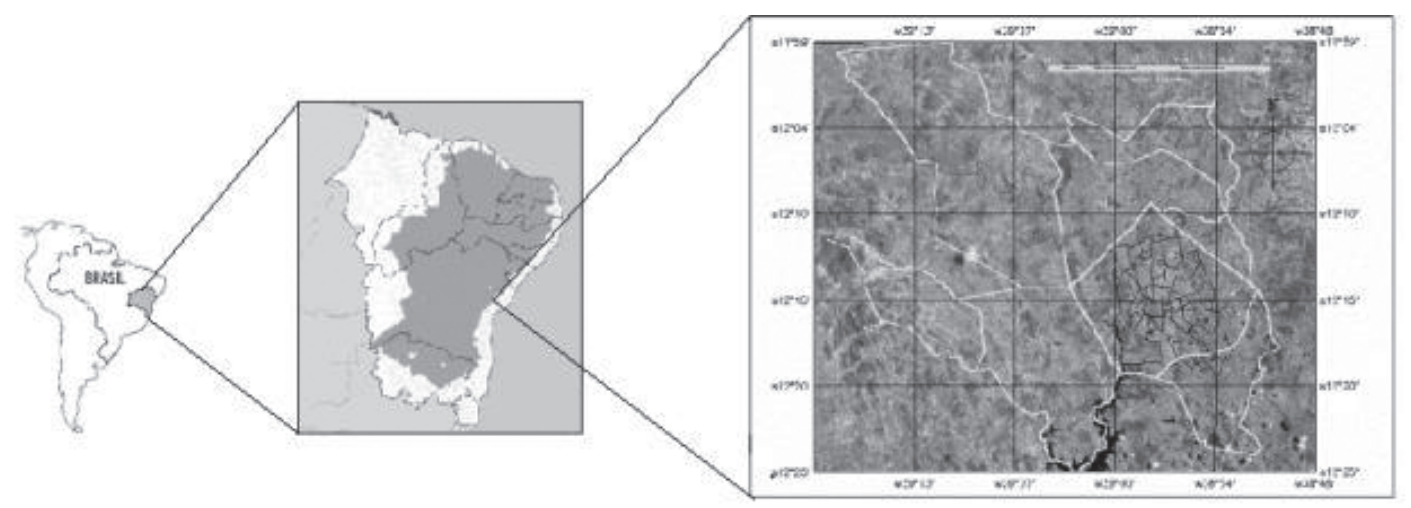

(a)

(b)

(c)

Este município localiza-se no Estado da Bahia Nordeste do Brasil, em área de transição entre o clima úmido do litoral e a região seca do semi-árido (b) em laranja, da América do Sul (a). Em a figura c observa-se a divisão distrital, sob imagem do sensor CCD do satélite CBERS2, em composição colorida RGB 342 de 06/ 03/2006.

Fonte: Elaboração própria. 
Segundo Andrade e Santos (2006), a sua tipologia climática está inserida na zona de transição entre o Agreste e o Semi-Árido. Possui como uma de suas peculiaridades a concentração dos índices pluviométricos no período do outono-inverno. Para Thornthwaite \& Matther (1955), o clima do município é o C2rA'a' (seco subúmido, megatérmico), possuindo temperaturas em média de $24^{\circ} \mathrm{C}$ e precipitações médias em torno de $848 \mathrm{~mm}$ anuais (Estação Climatológica, 2006).

Percebe-se a partir da análise da Figura $N^{0} 2$, a distinção em duas estações bem definidas com a predominância de temperaturas médias elevadas no verão em torno de $28^{\circ} \mathrm{C}$ e pluviosidade entre 50 e 70 $\mathrm{mm}$, enquanto o inverno é marcado por temperaturas médias baixas se comparadas com o verão, pois oscila em torno de $21^{\circ} \mathrm{C}$ e pluviosidade com índices mais elevados em torno de $90 \mathrm{~mm}$. Salientando que a amplitude térmica anual caracteriza-se em torna de $10^{\circ} \mathrm{C}$, porém em relação à amplitude diária é em torno de $7^{\circ} \mathrm{C}$ no verão e no inverno de $12^{\circ} \mathrm{C}$ em média, isso pode ser percebido a partir da análise da Figura 02, quando no inverno há um decréscimo dos valores de temperatura.

Quanto à geomorfologia do município, este localiza-se no Pediplano Sertanejo, na unidade geomorfológica dos Tabuleiros
Figura $\mathrm{N}^{\circ} 2$

GRÁFICO TERMO-PLUVIOMÉTRICO DO MUNICÍPIO DE FEIRA DE SANTANA (1997-2006)

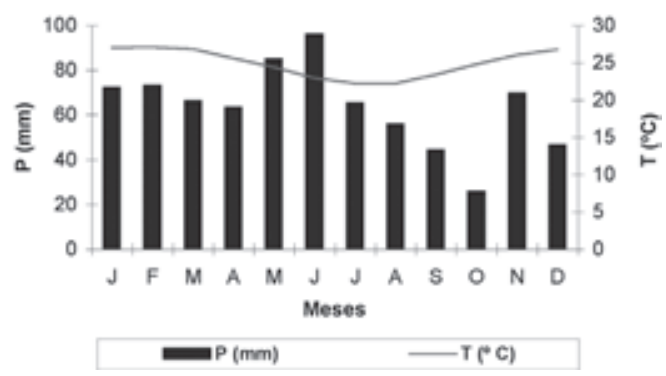

Fonte: Elaboração própria.

Costeiros Interioranos, que são características de superfícies descontinuas modeladas e tabulares. A evolução do relevo na região é resultante da alternância de diferentes sistemas morfoclimáticos estando vinculado as grandes mudanças climáticas que ocorreram desde o Mioceno até o presente. Geologicamente, o município possui duas formações: o embasamento cristalino Précambriano, constituído basicamente por granitos-gnaisses; e outra sedimentar de idade Pliocênica composta por conglomerados, areias e argila.

A vegetação predominante na área é a Caatinga, sendo que está em processo de

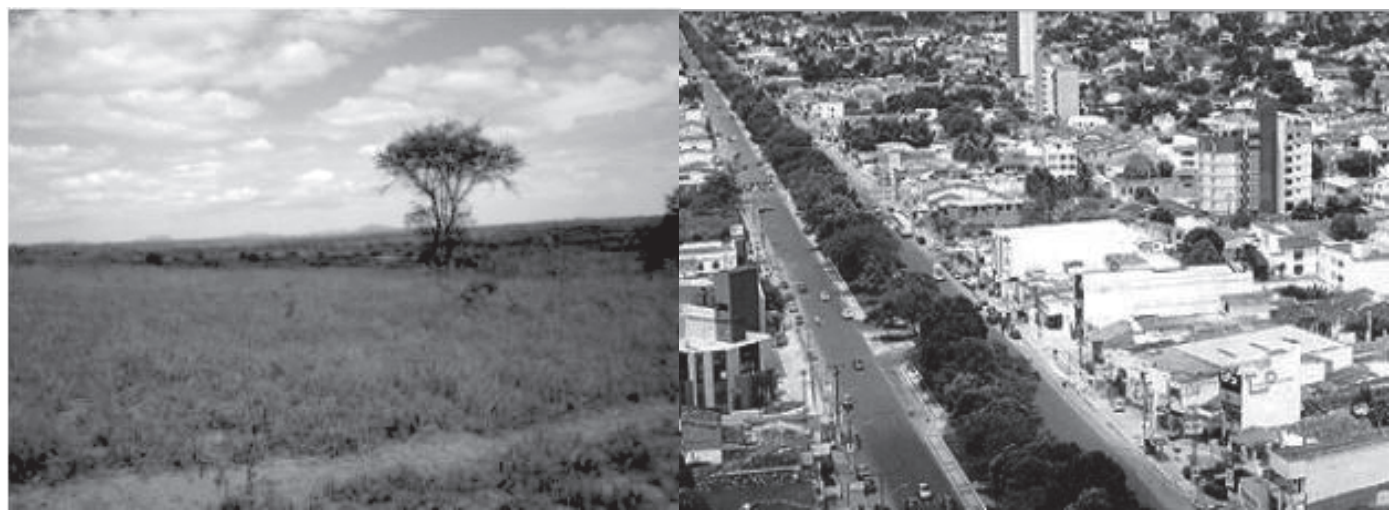

Fonte: Coleção pessoal dos autores. 
degradação pela ação antrópica, cuja extensão, as espécies e principais características de paisagem climatobotânica podem ser observadas na Figura N³a, ou seja, uma vegetação residual rasteira com a ocorrência de espaços mais densos de caatinga. Quanto a sua morfometria, o município pode ser divido em três porções: oeste, central e leste. O relevo tabuliforme feirense manifesta inúmeras depressões que acumulam água pluvial e freática dando origem às diversas lagoas na cidade. No que se refere à hidrografia a região é divisor de água de três importantes bacias, sendo nascente de duas delas: do Pojuca e do Subaé, e do Jacuípe (Santos et al., 2007).

\section{Metodologia}

\section{Materiais}

Foram utilizados neste artigo os dados climáticos da Estação Climatológica $N^{\circ}$ 83221, lotada no Departamento de Tecnologia (DTEC), localizada no campus da Universidade Estadual de Feira de Santana (UEFS), salientando que a estação é ligada ao Instituto Nacional de Meteorologia (INMET) destacando os de temperatura e umidade para realizar a aplicação no Índice de Thom \& Bosen (1959). Salientando que estes dados foram processados no software estatístico Microsoft Excel.

\section{Método}

O método consistiu numa revisão bibliográfica acerca das publicações sobre conforto térmico urbano, seguida de seleção de metodologias sobre quantificação e qualificação do conforto térmico. Após esta etapa, os dados de temperatura do bulbo seco e úmido, selecionados entre o período de 1998 e 2006, foram obtidos, através da Estação Climatológica No 83221 do DTEC/ UEFS. Salientamos que o período utilizado por conta da disponibilidade de dados confiáveis na cidade em questão.

Em seguida, realizou-se a classificação dos dados utilizando o software Excel 2000 na análise estatística e setorização dos dados, pelas estações do ano, selecionando os valores máximos e mínimos. Aplicou-se então a metodologia proposta por Thom \& Bosen (1959), que consiste num Índice de Temperatura Efetiva (TE) obtida através da primeira equação:

$$
\mathrm{TE}=0,4(\mathrm{Ts}+\mathrm{Tu})+4,8
$$

Onde $\mathrm{TE}=$ Temperatura Efetiva; $\mathrm{Ts}=$ temperatura do bulbo seco; e $\mathrm{Tu}=$ temperatura do bulbo úmido

De acordo com esse índice, o valor da TE é compreendida entre $18{ }^{\circ} \mathrm{C}$ a $25,6{ }^{\circ} \mathrm{C}$ como faixa de conforto; a TE abaixo de 17,9 é considerada como condição de

Quadro $\mathrm{N}^{\circ} 1$

DISTRIBUIÇÃO DAS CLASSES DO CONFORTO TÉRMICO

\begin{tabular}{|l|c|}
\hline Descrição & Classes do desconforto (TE) \\
\hline Bem estar & $\mathrm{TE}<21$ \\
Menos de 50\% da população possui um ligeiro desconforto & $21 £ \mathrm{TE}<24$ \\
Outros 50\% da população possui um crescente desconforto & $24 £ \mathrm{TE}<27$ \\
A maioria da população possui um relativo desconforto e & \\
há um significativo deterioramento da condição psicofísica & $27 £ \mathrm{TE}<29$ \\
Todos possuem um forte desconforto & $29 £ \mathrm{TE}<32$ \\
Estado de emergência médica, um desconforto muito forte & $\mathrm{TE}$ - 32 \\
\hline
\end{tabular}

Fonte: Thom \& Bosen (1959). 
stress ao frio; e acima de $25,6^{\circ} \mathrm{C}$ significa stress ao calor.

Assim, utilizando a metodologia de Monteiro e Mendonça (2003), analisou-se, de forma sistêmica, os resultados a fim de gerar uma estimativa de conforto térmico para a cidade de Feira de Santana-BA. O indice resultante foi comparado e classificado segundo os valores determinados no Quadro $N^{0} 1$, proposto também por Thom \& Bosen (1959), para integrar os dados de TE e entender como cada resultado tem sua repercussão no corpo humano.

\section{Resultados e discussão}

\section{O conforto térmico}

Compreender o conforto térmico e suas influências no Homem remete-nos a entender como se processa esse parâmetro do clima urbano nas grandes e médias cidades, através de suas diversas formas de ser classificado e quantificado. Monteiro e Mendonça (2003) propõe um sistema que engloba algumas variáveis na análise do clima urbano como: o Canal I (Termodinâmico), o Canal II (Físico Químico) e o Canal III (Hidrometeórico). Estas terminologias referem-se, respectivamente, ao conforto térmico, à qualidade do ar e aos impactos meteóricos.

Diante disso, Monteiro e Mendonça (2003: 24) afirma que o "conforto térmico engloba as componentes termodinâmicas que, em suas relações, se expressam através do calor, ventilação e umidade nos referenciais básicos a esta noção". É um filtro perceptivo significativo, pois afeta a todos permanentemente. Constitui, seja na Climatologia Médica, seja na tecnologia habitacional, assunto de investigação e importância crescente.

De acordo com Silva et al. (2003), a sensação de conforto térmico está associada ao ritmo de troca de calor entre o corpo humano e o meio ambiente. Nesse sentido, o desempenho humano durante qualquer atividade deve ser otimizado, desde que o ambiente propicie condições de conforto e que sejam evitadas as sensações desagradáveis, tais como dificuldade de eliminar o excesso de calor produzido pelo organismo, perda exagerada de calorias pelo corpo e desigualdade de temperatura entre as diversas partes do corpo.

O conforto térmico pode ser analisado de duas maneiras: a do ponto de vista pessoal, que leva em conta a confortabilidade do indivíduo em determinados ambientes; e a linha climato-ambiental, que propõe o estabelecimento de um estado térmico, levando em consideração as variáveis físicas como temperatura, umidade do ar, radiação e vento. É neste contexto que diversos autores propuseram índices para estudar mais profundamente a quantificação do conforto térmico.

Um parâmetro bastante utilizado para regiões frias é o método de Temperatura Equivalente de Windchil (TW). Esse método não foi aplicado posto que não se adequa à nossa realidade, uma vez que nessa metodologia os valores máximos de temperatura não ultrapassam os $20^{\circ} \mathrm{C}$. Assim, os valores do conforto térmico são obtidos a partir da equação de Windchil (Ames \& Insley, 1975), derivada de Siple \& Passel (1945) representadas por:

$$
\mathrm{T}_{\mathrm{W}}=\frac{(10 \mathrm{x} \sqrt{\mathrm{v}}+10,45-\mathrm{v}) \mathrm{x}(\mathrm{T}-33)}{22}+33
$$

E que pode ser simplificada para:

$$
T_{W}=[(10 x \sqrt{v}+10,45-v) \times(T-33)+726] / 22
$$

Onde: $v$ é a velocidade do vento em $\mathrm{m} / \mathrm{s}$ e $T$ é a temperatura do ar em graus Celsius.

Essa fórmula é derivada de Siple, que estabelece uma relação para quantificar os valores de perda de calor de um indivíduo a determinadas condições de temperatura e vento. Um outro método bastante utilizado pela Física é a Teoria dos Ambientes Quentes, que afirma que cada indivíduo possui seu próprio balanço de energia, e este é resultado das trocas de calor por radiação, convecção dentre outros, assim cabe ao corpo humano termorregular-se.

Nesse sentido, o conforto térmico está associado ao modo de vida das pessoas que vivem nas cidades, pois com o processo de 
urbanização este parâmetro climático está cada vez mais intenso, fato que ocasiona sua elevação e diminuição tanto da qualidade de vida quanto dos aspectos gerais da saúde humana nas cidades sejam elas principalmente de grande e de médio porte.

\section{Análise das temperaturas de bulbo seco e úmido}

A partir da aplicação dos dados selecionados, obtivemos as variações de temperatura de bulbo seco (ar) e de bulbo úmido entre 1998 e 2006, organizando o banco de dados de acordo com a estação do ano, em que se constataram altas temperaturas de bulbo seco principalmente nas estações do verão com um máximo de $37,9{ }^{\circ} \mathrm{C}$ no ano de 2006 e outro na primavera com 37,6 ${ }^{\circ} \mathrm{C}$ no ano de 2004. Quanto às mínimas, as menores temperaturas de bulbo seco ocorreram na primavera, com a mínima das mínimas de $17,4{ }^{\circ} \mathrm{C}$ registrada no ano de 1999 (Figura Nº4).

Figura $\mathrm{N}^{\circ} 4$

VARIAÇÃO SAZONAL DAS TEMPERATURAS DE BULBO SECO E ÚMIDO

(1998-2006)
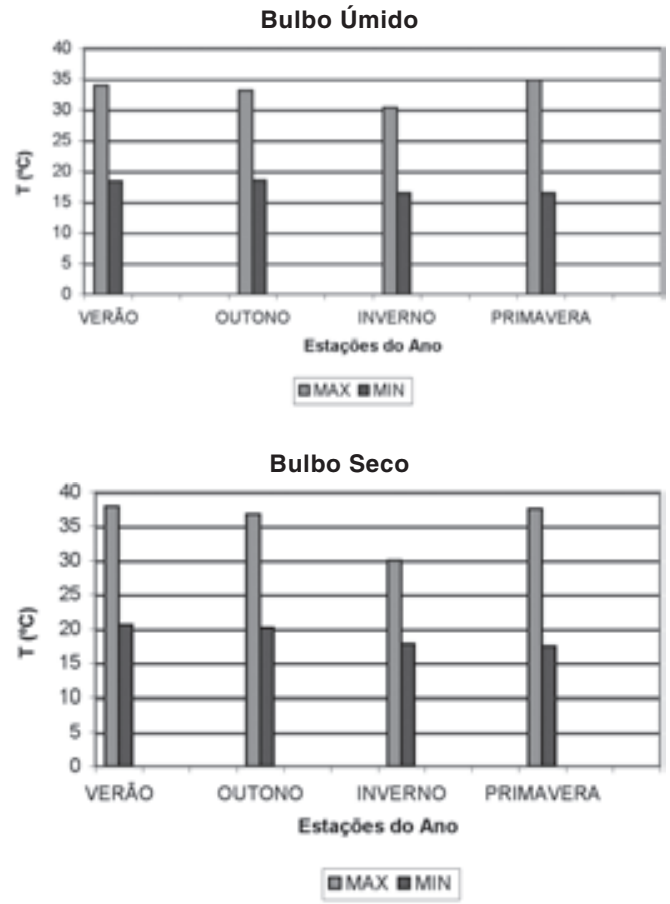

Fonte: Elaboração própria.
Com base na análise dos dados do termômetro de bulbo úmido, que serve de base para obtenção da umidade relativa, constatou-se que as maiores temperaturas estão na primavera com $34,8{ }^{\circ} \mathrm{C}$, registradas no ano de 1998 e as mínimas no inverno; e, na primavera, sendo os dois registros no ano de 2006. Percebe-se também uma grande amplitude térmica sazonal entre os dados máximos e mínimos de ambos termômetros.

\section{Geração dos índices de temperatura efetiva (te)}

A partir da integração dos dados ao índice proposto por Thom \& Bosen (1959), constatou-se que, através da setorização dos dados climáticos por estação do ano, a correlação dos dados resultou em 0,4 o que nos mostra uma fraca correlação dos dados, que pode ser atribuída diferença dos dados quanto a sua obtenção e finalidade.

Nos resultados do verão, obteve-se um Índice de Temperatura Efetiva (TE) máxima de $33,5{ }^{\circ} \mathrm{C}$ e um valor mínimo de $20,4{ }^{\circ} \mathrm{C}$, o que demonstra, a partir da análise do diagrama, que ocorreu um estado de emergência médica, possuindo um desconforto muito forte, com uma TE acima de $32{ }^{\circ} \mathrm{C}$; nas mínimas, obteve-se o valor de $20,4{ }^{\circ} \mathrm{C}$ o que mostra um estado de bem estar com base no diagrama. (Figura $N^{\circ} 5$ e Quadro $N^{\circ} 2$ )

Já no outono ocorreu uma redução do índice de TE com valores máximos de 32,7 ${ }^{\circ} \mathrm{C}$, caracterizado como um estado de desconforto muito forte; enquanto nos valores mínimos houve uma redução mínima de $0,2{ }^{\circ} \mathrm{C}$, registrando-se $20,2{ }^{\circ} \mathrm{C}$ o que também, de acordo com o diagrama, demonstra um estado de bem estar.

No que se refere à aplicação deste índice no período correspondente ao inverno, ocorreu uma redução considerável na TE máxima para $28,9{ }^{\circ} \mathrm{C}$, isto é, uma redução de $4,6{ }^{\circ} \mathrm{C}$ na variação sazonal de verão-inverno, que, a partir da análise do diagrama, demonstrou ser equivalente a um relativo aumento do desconforto. Quanto a TE mínima, obteve-se uma queda dos valores com relação ao verão, de $1,9^{\circ} \mathrm{C}$, registrando a temperatura de $18,5^{\circ} \mathrm{C}$, a qual se enquadra no diagrama em um estado de bem estar (Figura No 5 e Quadro No 2). 
Figura $N^{\circ} 5$

VARIAÇÃO DAS TEMPERATURAS EFETIVAS PARA FEIRA DE SANTANA-BA

(1998 A 2006)

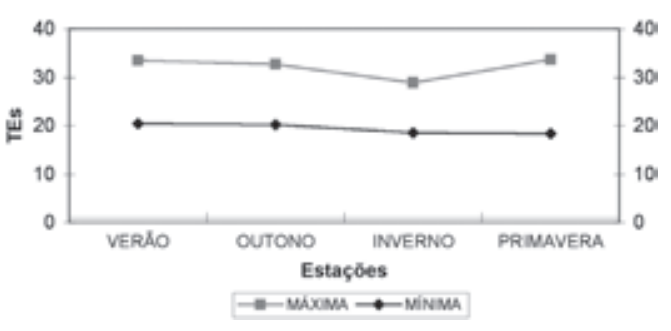

Fonte: Elaboração própria.

Na estação da primavera, a TE máxima apresentou-se como a maior em relação a todas as outras estações, registrando 33,7 ${ }^{\circ} \mathrm{C}$, ou seja, $0,2{ }^{\circ} \mathrm{C}$ a mais em contraponto aos dados do verão, que, de acordo com o diagrama, apresenta um desconforto muito forte e nos registros mínimos obteve-se o valor de $18,3{ }^{\circ} \mathrm{C}$, o menor índice de TE dentre todas as estações. Nesse sentido, a cidade em estudo apresenta um desconforto térmico muito elevado durante quase todo o ano, com exceção do inverno. Quanto ao aspecto de emergência médica, está associada com a propensão de ocorrer algum problema ligado ao biorritmo das pessoas da cidade de Feira de Santana.

Pode-se perceber, com a integração dos dados no índice, que os valores de TE oscilam nos valores máximos em todas as estações, de $28,9{ }^{\circ} \mathrm{C}$ no inverno até $33,7{ }^{\circ} \mathrm{C}$ na primavera, o que nos mostra uma amplitude máxima sazonal significativa de $4,8{ }^{\circ} \mathrm{C}$; e nos valores mínimos uma variação sazonal mínima das $\mathrm{TE}^{\prime} \mathrm{s}$ de $2,1{ }^{\circ} \mathrm{C}$. Uma particularidade encontrada através deste estudo foi que tanto os valores de TE máximo e mínimo estão na estação da primavera e não no verão e inverno respectivamente.

Quadro $N^{\circ} 2$

CLASSIFICAÇÃO DO CONFORTO TÉRMICO PARA FEIRA DE SANTANA-BA

\begin{tabular}{|c|c|c|}
\hline Descrição & $\begin{array}{c}\text { Classes do } \\
\text { desconforto (TE) }\end{array}$ & Classes de feira de santana-ba \\
\hline Bem estar & $\mathrm{TE}<21$ & $\begin{array}{l}\text { Todas as TE's das estações nos valores } \\
\text { mínimos verão }\left(20,4{ }^{\circ} \mathrm{C}\right) \text {, outono } \\
\left(20,2^{\circ} \mathrm{C}\right) \text {, inverno }\left(18,5^{\circ} \mathrm{C}\right) \text { e } \\
\text { primavera }\left(18,3^{\circ} \mathrm{C}\right)\end{array}$ \\
\hline $\begin{array}{l}\text { Menos de } 50 \% \text { da população } \\
\text { possui um ligeiro desconforto }\end{array}$ & $21 £ \mathrm{TE}<24$ & Nenhum registro \\
\hline $\begin{array}{l}\text { Outros } 50 \% \text { da população } \\
\text { possuem um crescente } \\
\text { desconforto }\end{array}$ & $24 £ \mathrm{TE}<27$ & Nenhum registro \\
\hline $\begin{array}{l}\text { A maioria da população } \\
\text { possui um relativo } \\
\text { desconforto e há um } \\
\text { significativo deterioramento } \\
\text { da condição psicofísica }\end{array}$ & $27 £ \mathrm{TE}<29$ & $\begin{array}{l}\text { TE do inverno no valor máximo } \\
\left(28,9^{\circ} \mathrm{C}\right)\end{array}$ \\
\hline $\begin{array}{l}\text { Todos possuem um forte } \\
\text { desconforto }\end{array}$ & $29 £ \mathrm{TE}<32$ & Nenhum registro \\
\hline $\begin{array}{l}\text { Estado de emergência } \\
\text { médica, um desconforto } \\
\text { muito forte }\end{array}$ & $\mathrm{TE}{ }_{-} 32$ & $\begin{array}{l}\text { TE's de valores máximos do verão } \\
\left(33,5^{\circ} \mathrm{C}\right) \text {, outono }\left(32,7^{\circ} \mathrm{C}\right) \\
\text { e primavera }\left(33,7^{\circ} \mathrm{C}\right)\end{array}$ \\
\hline
\end{tabular}

Fonte: Elaboração própria, adaptado de Thom \& Bosen (1959). 
Salientando que a diferença nos valores de TE tanto das máximas como das mínimas é de apenas $0,2{ }^{\circ} \mathrm{C}$ (Quadro $\mathrm{N}^{\circ} 2$ ).

\section{Considerações finais}

Analisar o conforto térmico é uma tarefa muito complexa por abranger diversas variáveis que devem ser consideradas. Nesta pesquisa, foram utilizados estes índices e teorias citadas no decorrer deste artigo para classificar e quantificar o conforto térmico na cidade de Feira de Santana-Ba.

Os métodos de abordagem aqui expostos apresentam uma regularidade quanto aos modelos teóricos, como o de Monteiro e Mendonça (2003), baseados na análise sistêmica dos elementos do clima e, principalmente, os componentes do conforto térmico. Os métodos de quantificação como o de Thom \& Bosen (1959), que quantifica as Temperaturas Efetivas (TE); e o índice de Windchil que, mesmo não aplicável ao nosso estudo apresenta uma forma inovadora de análise do conforto térmico, porém para regiões com baixas temperaturas.

Pode-se afirmar que a metodologia de Thom \& Bosen (1959) mostrou-se satisfatória quanto à aplicação dos dados e seus resultados, pois expressam a realidade climática da cidade Feira de Santana-BA. Vale salientar que os resultados foram caracterizados por períodos com um grande índice de TE, ou seja, altas taxas de conforto térmico e outros com valores baixos, destacando os meses da primavera que apresentaram as mais altas e baixas temperaturas efetivas. Nesse sentido, reafirmamos a necessidade de dados climatológicos com maior representatividade no que tange ao tamanho da série utilizada, para promover uma investigação mais aprofundada.

\section{Referências}

AMES, D. \& INSLEY, L. W. Windchill effect for cattle and sheep. J Anim Sci, 1975, $N^{\circ} 40$, p. 161-165.

ANDRADE, H. O. e SANTOS R. L. A condição termal em Feira de Santana-Ba: uma análise do conforto térmico. In: UFMT.
VII Simpósio de Climatologia Geográfica. Rondonópolis - MT: UFMT, 2006.

DIVISÃO DE SENSORIAMENTO REMOTO - DSR. XIII Simpósio Brasileiro de Sensoriamento Remoto. Florianópolis-SC: Divisão de Sensoriamento Remoto - DSR, 2007, p. 2.939-2.946.

ESTAÇÃO CLIMATOLÓGICA. Banco de Dados Meteorológicos 1997 - 2006. Feira de Santana: UEFS / DTEC / INMET, 2007.

FANGER, P. O. Thermal Confort. New York: McGraw-Hill Book Company, 1970.

LOMBARDO, M. A. Ilha de calor nas metrópoles: o exemplo de São Paulo. São Paulo: Hucitec, 1985.

MONTEIRO, C. A. F. Teoria e clima e urbano. São Paulo: IGEO/USP, 1976.

MONTEIRO, C. A. F. e MENDONÇA, F. (Org.). Clima Urbano. São Paulo: Contexto, 2003.

SANTOS, R. L.; DE OLIVEIRA, A.; LIMA, A.; MOTA, K. e SANTO, S. O uso da técnica de sensoriamento remoto para a localização de lagoas no município de Feira de Santana - BA. In: DSR. Anais XIII Simpósio Brasileiro de Sensoriamento Remoto. Florianópolis SC: Divisão de Sensoramento Remoto DSR, 2007, p. 2.939-2.946.

SILVA, E. M.; CORREA, D. M. e RIBEIRO, A. G. O Conforto Térmico na cidade de Uberlândia-Mg. II Simpósio Regional de Geografia. Uberlândia: Universidade Federal de Uberlândia, 2003. Disponível em Internet: http://www.ig.ufu.br/2srg/3/3-54B.pdf.

SIPLE, P. \& PASSEL, C. Measurements of dry atmospheric cooling in subfreezing temperatures. Proceedings of the American Philosophical Society, 1945, Vol. 89, № 1, p. 177-199.

THOM, E.C. \& BOSEN, J.F. The discomfort index. Weatherwise. 1959; No 12, p. 57 - 60.

THORNTHWAITE, C. W. \& MATHER, J. R. The water balance. Centerton: Drexel Institute of Technology, Laboratory of climatology, 1955, Vol. VIII, No 1. 